\title{
PENGARUH LAYANAN KONSELING KELOMPOK TEKNIK COGNITIVE RETRUCTURING (CR) TERHADAP MOTIVASI BELAJAR SISWA
}

\author{
Retno Apit Kurniawan, Awik Hidayati, Aldila Fitri Radite Nur M.
}

Program Studi Bimbingan dan Konseling, Universitas Veteran Bangun Nusantara Email: kurniatilia164@gmail.com

\begin{tabular}{|c|c|}
\hline Article Info & Abst \\
\hline $\begin{array}{l}\text { Available online } \\
15.06 .2019\end{array}$ & $\begin{array}{l}\text { Penelitian ini merupakan peneliti eksperimen dengan menggunakan sampel sebanyak } 7 \\
\text { siswa yang memiliki skors rendah dari } 36 \text { siswa. Pengumpulan data dengan menggunakan skala } \\
\text { psikologi, diberikan sebanyak dua kali yakni sebelum diberikan tindakan dan sesudah diberikan } \\
\text { tindakan, tindakan tersebut berupa layanan konseling kelompok teknik cognitive retructuring. } \\
\text { Data yang terkumpul selanjutnya dianalisis dengan menggunakan teknik pengolahan data statitiska } \\
\text { uji z Wilcoxon. Variabel yang diteliti dalam penelitian ini adalah layanan konseling kelompok } \\
\text { sebagai variabel bebas dan motivasi belajar sebagai variabel terikat. Berdasarkan hasil penelitian } \\
\text { dan analisis data yang diperoleh penelitian pada siswa kelas XI IPS } 3 \text { SMA Negeri } 1 \text { Tawangsari } \\
\text { terdapat pengaruh layanan konseling kelompok melalui Teknik Cognitive Retructuring untuk } \\
\text { meningkatkan Motivasi Belajar pada siswa kelas XI IPS } 3 \text { SMA Negeri } 1 \text { Tawangsari Sukoharjo } \\
\text { tahun ajaran 2018/2019 hasilnya dapat disimpulkan sebagai berikut: Motivasi belajar siswa } \\
\text { sebelum mendapatkan layanan konseling kelompok rendah dengan skors rata }- \text { rata } 33,625 \text {. } \\
\text { Setelah mendapatkan layanan konseling kelompok skor rata }- \text { rata naik menjadi } 65,63 \text {. } \\
\text { Berdasarkan analisis data dengan uji tes dapat dilihat bahwa } t_{o}=2,366 \text { sedangkan tabel nilai kritis } \\
\text { wilcoxon pada taraf signifikasi } 5 \% \text { diperoleh } z_{t}=2,00 \text { dengan demikian } z_{o}>z_{t} \text {. Maka dapat } \\
\text { disimpulkan bahwa layanan konseling kelompok berpengaruh terhadap motivasi belajar siswa di } \\
\text { kelas XI IPS } 3 \text { SMA Negeri } 1 \text { Tawangsari, artinya semakin besar frekuensi layanan konseling } \\
\text { kelompok, semakin tinggi motivasi belajar siswa. }\end{array}$ \\
\hline
\end{tabular}

Kata kunci: modul, ketrampilan dasar konseling, konseling

\section{Abstract}

This study is an experimental researcher using a sample of 7 students who had a low suspension of 36 students. Data collection using a psychological scale was given twice namely before being given the action and after being given the action, the action was in the form of counseling services for cognitive retructuring technique group. The collected data is then analyzed using statistical data processing techniques Wilcoxon $z$ test. The variables examined in this study were group counseling services as independent variables and learning motivation as the dependent variable. Based on the results of research and data analysis obtained in the XI IPS 3 students of SMA 1 Tawangsari there was the influence of group counseling services through Cognitive Retructuring Techniques to increase Learning Motivation in IPS XI 3 students of SMA 1 Tawangsari Sukoharjo the 2018/2019 school year. concluded as follows: Student learning motivation before getting low group counseling services with an average suspension of 33,625. After getting counseling services the group scores increased on average to 65.63. Based on data analysis with test tests it can be seen that to $=2.366$ while the critical value table Wilcoxon at the significance level of $5 \%$ is obtained $z t=2.00$ thus zo> zt. Then it can be concluded that the group counseling service influences students 'motivation in class XI IPS 3 in SMA 1 Tawangsari, meaning that the greater the frequency of group counseling services, the higher students' learning motivation.

Keywords: Group Counseling, Cognitive Retructuring Technique, Learning Motivation

\section{PENDAHULUAN}

Generasi muda adalah sumber sumber daya manusia yang sangat diharapkan oleh setiap bangsa, terutama bangsa Indonesia. Berbagai upaya sedang dilaksanakan oleh bangsa Indonesia untuk meningkatkan kualitas sumber daya manusia Indonesia. Sumber daya manusia yang berkualitas 
adalah modal dasar sekaligus kunci keberhasilan pembangunan nasional. Jika sumber daya manusia Indonesia memiliki kualitas yang baik, maka Indonesia bisa menjadi negara yang maju.

Terwujudnya sumber daya manusia yang berkualitas tidak terlepas dari peranan dunia pendidikan. Pendidikan adalah usaha sadar dan terencana untuk mewujudkan suasana belajar dan proses pembelajaran agar peserta didk secara aktif mengembangkan potensi dirinya untuk memiliki kekuatan spiritual keagamaan, pengendalian diri, kepribadian, kecerdasan, akhlak mulia, serta keterampilan yang diperlukan dirinya, masyarakat, bangsa dan negara (UUSPN No. 20 tahun 2003) jadi, dapat disimpulkan bahwa pendidikan adalah ujung tombak kemajuan suatu bangsa.

Motivasi memiliki peranan yang sangat penting dalam aktivitas tiap individu dalam belajar. Siswa yang memiliki motivasi tinggi dalam belajar menampakkan minat besar dan perhatian yang penuh terhadap tugas - tugas belajar. Mereka memusatkan banyak energi fisik maupun psikis terhadap kegiatan belajar tanpa mengenal rasa bosan apalagi menyerah. Sebaliknya siswa yang memiliki motivasi rendah menampakkan keengganan, cepat bosan, dan berusaha menghindar dari proses belajar mengajar. Gleitman, (2010: 100) mengemukakan pengertian dasar motivasi ialah keadaan internal organisme baik manusia ataupun hewan yang mendorongnya untuk berbuat sesuatu. Dalam pengertian ini motivasi berarti pemasok daya untuk bertingkah laku secara terarah.

Tilaar, (2006: 42) mengemukakan Belajar adalah merupakan proses dasar dari perkembangan hidup manusia, dengan belajar manusia melakukan perubahan perubahan sehingga tingkah lakunya dapat berkembang. Sedangkan menurut Nugroho (2014) belajar adalah suatu proses seseorang dalam mempelajari suatu hal sehingga timbul perubahan dari belum mampu menjadi mampu dalam diri orang tersebut karena individu memperoleh pengetahuan dari proses tersebut. Proses belajar tidak terjadi di dalam ruang kosong, data, ilmu pengetahuan, hanya dapat diserap dalam kaitanya dengan dunia nyata, terutama bagi peserta didik muda dibangku pendidikan dasar. Hal senada dijelaskan oleh Tilaar, (2004: 42) dengan belajar manusia melakukan perubahan - perubahan sehingga tingkah lakunya dapat berkembang. Proses belajar tidak terjadi dalam ruang kosong, data, ilmu pengetahuan, hanya dapat diserap dalam kaitanya dengan dunia nyata, terutama bagi peserta didik muda di bangku pendidikan dasar.

Motivasi belajar merupakan kekuatan, daya pendorong atau alat pembangun kesediaan dan keinginan yang kuat dalam diri peserta didik untuk belajar secara aktif, kreatif, inovatif dan menyenangkan dalam rangka perubahan perilaku, baik aspek kognitif, afektif, maupun psikomotorik. Motivasi belajar dapat di bangkitkan, ditingkatkan, dan pelihara oleh kondisi - kondisi luar, pereti penyajian pelajaran oleh guru dengan media yangbervariasi, metode yang tepat, komunikasi yang dinamis, dan sebagainya. Motivasi dapat berperan dalam penguatan belajar apabila seorang yang 
belajar dihadapkan pada suatu masalah yang memerlukan pemecahan, dan hanya dapat dipecahkan berkat bantuan hal - hal yang dilaluinya.

Menurut Sukardi, (2015: 148) Konseling Kelompok adalah konseling yang diselenggarakan dalam kelompok dengan memanfaatkan dinamika kelompok yang terjadi dalam kelompok itu. Masalah - masalah yang dibahas merupakan masalah perorangan yang muncul dalam kelompok itu yang meliputi berbagai masalah dalam segenap bidang bimbingan.

Menurut Prayitno, (2009) Tujuan layanan konseling kelompok terfokuskan adalah masalah pribadi individu, maka layanan konseling kelompok yang intensif dalam upaya pemecahan masalah tersebut, konseli memperoleh dua tujuan sekaligus yaitu : (1). Berkembangnya perasaan, pikiran, persepsi, wawasan dan sikap terarah kepada tingkah laku khususnya bersosialisasi dan komunikas.

(2). Terpecahnya masalah individu yang bersangkutan dan diperolehnya imbas cara pemecahan masalah tersebut dari individu - individu lain yang menjadi anggota konseling kelompok. Melalui layanan konseling kelompok teknik Cognitive Retructuring diharapkan siswa yang tingkat motivasinya rendah bisa termotivasi untuk lebih rajin dalam belajar.

Teknik Cognitive Retructuring adalah salah satu terapi perubahan perilaku yang membantu klien dengan cara membuang pikiran dan keyakinan buruk klien untuk kemudian diganti dengan kontruksi pola pikir yang lebih baik. Menurut Barriyah, (2009) mengatakan bahwa Cognitive Retructuring usaha memberi bantuan kepada klien agar siswa dapat mengevaluasi perilaku siswa dengan kritis dengan menitik beratkan pada hal pribadi yang negatif. Proses Cognitive Retructuring yang terjadi pada dir siswa sering kali mempunyai implikasi terhadap perubaan perilaku. Klien diajak untuk mengenal, mengamati dan memonitor gagasan dan asumsi siswa.

Cognitive Retructuring memusatkan perhatian pada upaya mengidentifikasi dan mengubah pikiran - pikiran atau pernyataan diri negatif dan keyakinan - keyakinan yang tidak rasional. Cognitive Retructuring menggunakan asumsi bahwa respon - respon perilaku dan emosional yang tidak adaptif dipengaruhi oleh keyakinan, sikap, dan persepsi ( kognisi ) klien. Dalam meningkatkan motivasi belajar pada siswa ialah dengan dengan melakukan konseling kelompok terhadap siswa yang memiliki motivasi belajar rendah.

Menurut Barriyah, (2009) tujuan dari teknik Cognitive Retructuring yaitu, antara lain: (1). Memberikan bantuan kepada klien agar dapat mengevaluasi perilaku siswa dengan kritis dan menitik beratkan pada hal pribadi yang negatif. (2). Agar klien tampil dalam mengenali dan mengamati sejauh mana pikiran dan perasaan pada saat itu. (3). Mengubah cara berfikir klien yang salah. (4). Agar klien dapat mengevaluasi perilaku siswa yang menitik beratkan pada hal pribadi yang negatif. Layanan konseling kelompok dalam pelaksanaanya menggunakan dinamika kelompok sebagai media 
kegiatan. Dinamika kelompok jika dapat dikembangkan dan dimanfaatkan secara baik dan efektif, maka layanan tersebut dapat berjalan dengan baik.

\section{METODE PENELITIAN}

Prosedur Penelitian, alur kerangka berpikir dalam penelitian ini digambarkan pada gambar 1 .

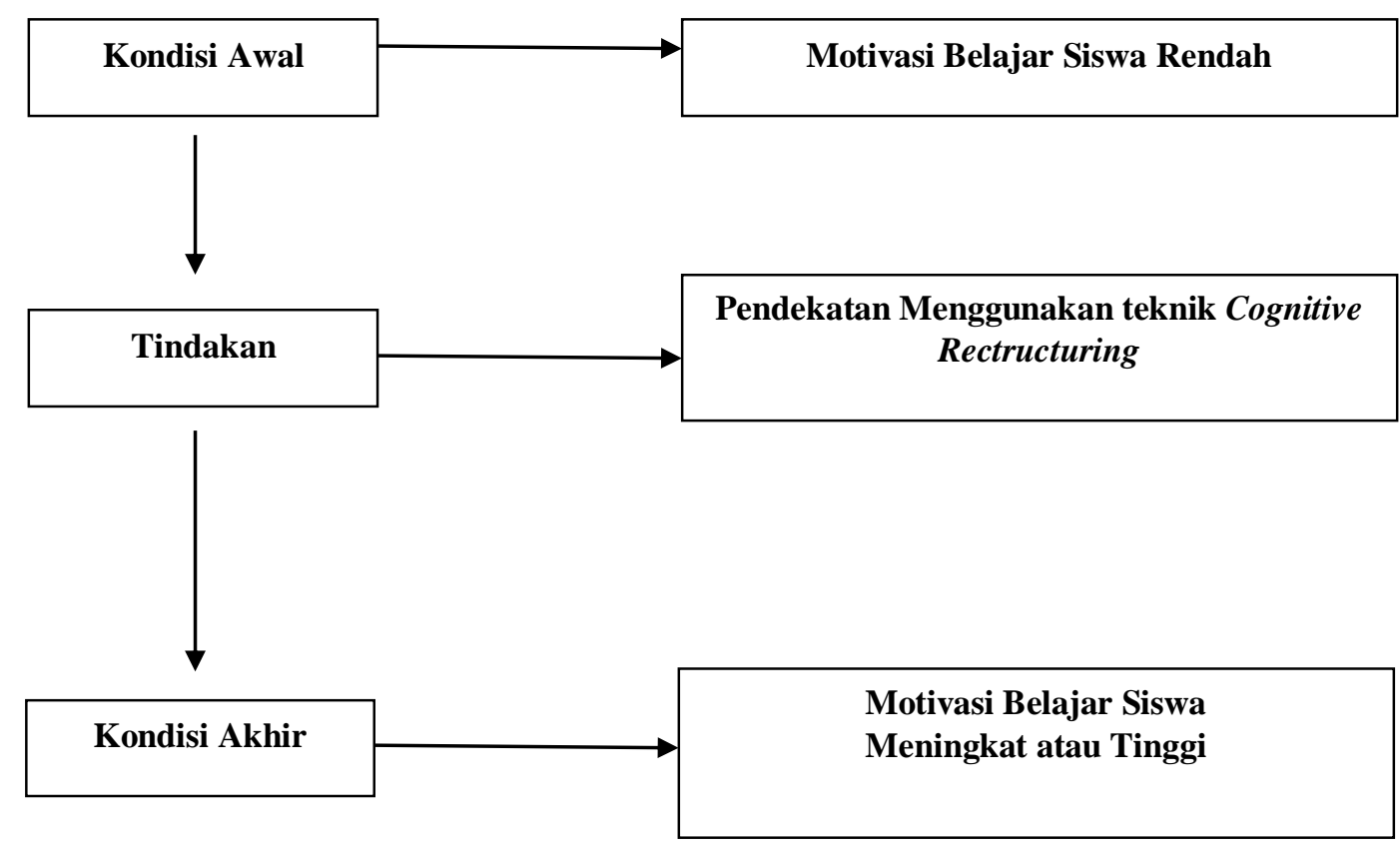

Gambar 1. Prosedur Penelitian

Subyek Penelitian, Metode penelitian adalah suatu cara atau kegiatan dalam usaha untuk menentukan, mengumpulkan, dan mengembangkan serta menguji suatu pengetahuan dengan menggunakan metode - metode ilmiah. Menurut Sirat, (2009: 40) pengertian metode penelitian adalah suatu cara memilih masalah masalah yang dan penentuan judul. Menurut Nasir, (2010: 51) metode penelitian merupakan cara utama yang digunakan peneliti untuk mencapai tujuan dan menentukan jawaban atas masalah yang diajukan.

Jenis Penelitian, dalam penelitian ini, metodelogi penelitian yang digunakan adalah metode ekpserimental yang bertujuan membuat paparan, gambaran atau lukisan secara sistematis, faktual dan akurat mengenai faktor - faktor, sifat - sifat antara fenomena untuk menjelaskan data yang digunakan waktu sekarang. Dalam penelitian ini peneliti menggunakan prosedur pretest and posttest desain. Pada desain ini terdapat satu kelompok yang digunakan untuk penelitian, kemudian diberi pretest untuk mengetahui keadaan awal dan diberi posttest setelah diberi layanan konseling kelompok apakah ada perbedaan sebelum dan sesudah diberi layanan. 
Teknik Analisi Data, Teknik analisa data adalah proses mengorganisasikan dan mengurutkan data ke dalam pola, kategori dan satu uraian dasar sehingga dapat ditemukan tema dan rumusan hipotesis kerja seperti yang disarankan oleh data. Data yang diperoleh dan dikumpulkan dari berbagai sumber kemudian dianalisa agar dapat memahami obyek yang diteliti. Analisa data dilakukan dalam proses, artinya dimulai sejak pengumpulan data dari awal secara intensif.

Dalam analisis data peneliti menggunakan metode analisis kuantitatif. Adapun rumus statistik yang digunakan adalah rumus Wilcoxon Signed.

Hasil Penelitian, untuk mengetahui seberapa besar tingkat motivasi belajar siswa XI IPS 3 sebelum diadakan layanan konseling kelompok, maka diadakan pembagian skala psikologi motivasi belajar dalam bentuk pre - test yang berjumlah 36 siswa kemudian dari siswa yang memiliki skor skala psikologi rendah terdapat 7 siswa. Dari 7 siswa yang skor skala psikologi motivasi belajar rendah tersebut belum mampu mengembangkan motivasi dalam diri mereka. Kemudian dari 7 siswa tersebut diajadikan subyek penelitian. Dari hasil presentase skor tersebut terdapat skor terendah 42.5 yaitu Athallah Nur Hudan dan Muhammad Vicky Rival.

Tabel 1. Hasil Pre - Test Skor Motivasi Rendah

\begin{tabular}{lllll}
\hline NO & KODE SUBYEK & JENIS KELAMIN & SKORS & PRESENTASE \\
\hline 1 & ANH & L & 68 & 42.5 \\
2 & AU & P & 70 & 43.75 \\
3 & EK & P & 69 & 43.125 \\
4 & FE & L & 69 & 43.125 \\
5 & GT & L & 70 & 43.75 \\
6 & MV & L & 68 & 42.5 \\
7 & RD & P & 70 & 43.75 \\
\hline
\end{tabular}

Kemudian dari 7 siswa tersebut diberikan layanan konseling kelompok teknik cognitive retructuring. Cognitive Retructuring adalah salah satu terapi modifikasi perilaku yang membantu klien dengan cara membuang pikiran tidak baik dan keyakinan buruk dari klien, untuk kemudian diganti dengan konstruksi pola pikir yang lebih baik. Dengan teknik ini diharapkan siswa mampu berfikir positif dalam meningkatn motivasi belajar memalalui layanan konseling kelompok tersebut. Perencanaan untuk meningkatkan motivasi pada gambar 2. 


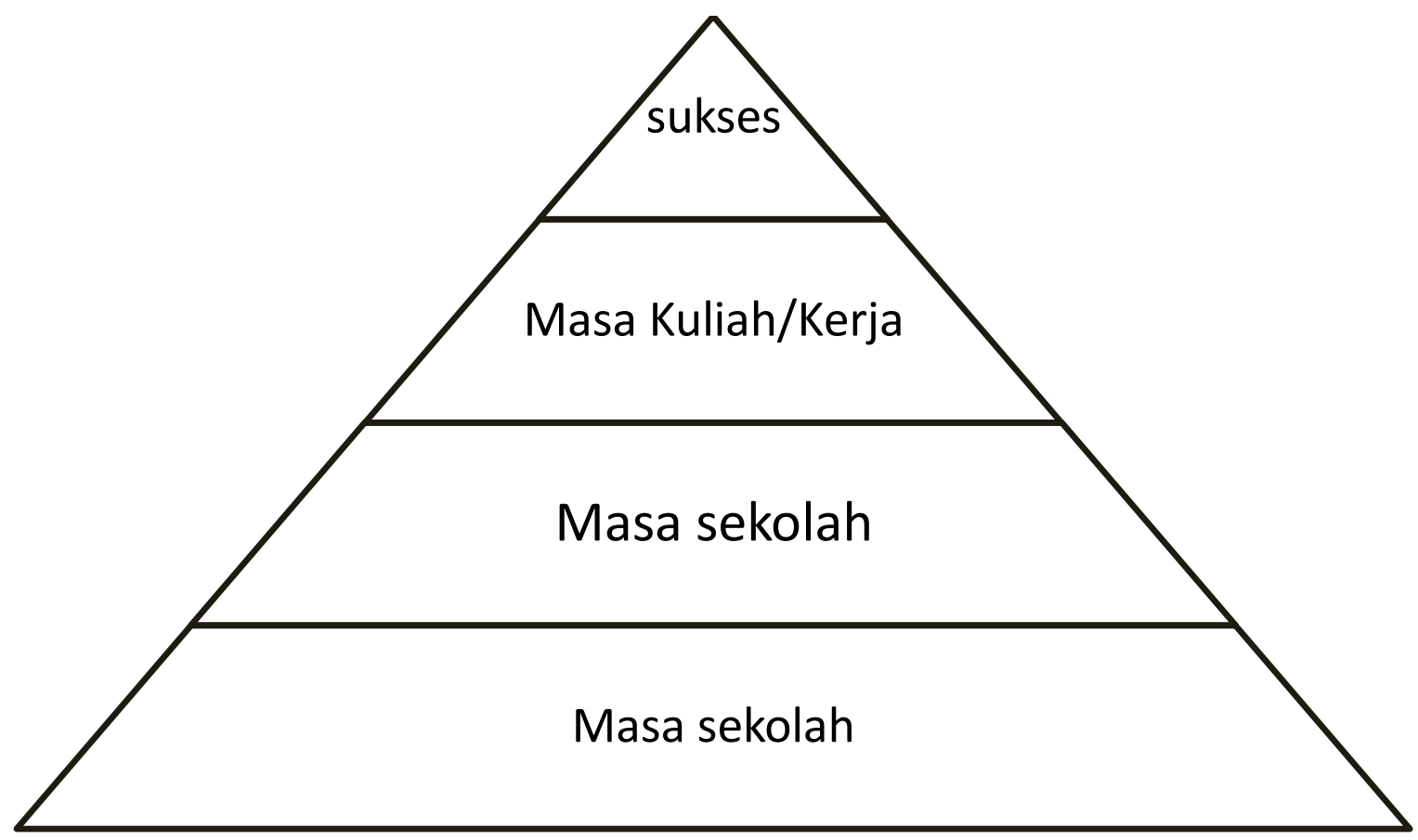

Gambar 2. Rencana Kerangka Layanan Konseling Kelompok.

Pada gambar tersebut menjelaskan bagaimana cara mencapai kesuksesan yaitu dengan cara merubah pola pikir dari malas belajar menjadi rajin belajar. Gambar diatas menunjukan lingkaran tersebut adalah responden atau siswa, untuk mencapai sukses siswa harus bersaing dengan siswa lainya dalam satu kelas maupun luar kelas dalam konteks dilingkungan sekolahan. Belajar yang efektif tidak terlalu lama namun sering atau ajeg. Dan untuk tahap selanjutnya setelah berhasil dalam lingkup sekolah, lalu tahap selanjutnya masa perkuliahan atau bekerja dengan memperhitungkan kemampuan bakat dan minat dan menuju tahap sukses. Jikapun tidak berhasil ingatlah tidak ada kata terlambat untuk memulai kembali dan kembalilah belajar. Jadi kunci menuju kesuksesan adalah belajar.

Selanjutnya yaitu Kegiatan Layanan Konseling Kelompok, layanan ini dimulai bulan April sampai bulan Mei 2019. Dalam layanan konseling kelompok pertemuan ke-1 pada Senin, 29 April 2019 ini yang harus disiapkan peneliti yaitu pre - test dan pembentukan kelompok. Pembentukan kelompok ini yaitu siswa yang memiliki skor skala psikologi motivasi rendah. Kemudian pertemuan ke-2 pada Rabu, 1 Mei 2019 peneliti memberikan penjelasan tentang apa itu layanan konseling kelompok, teknik - teknik dalam layanan konseling kelompok juga memberikan materi dasar tentang pemahaman diri. Untuk pertemuan ke-3 pada Senin, 6 Mei 2019 peneliti menjelaskan asas - asas tentang konseling kelompok dan juga melanjutkan pertemuan kemarin, peneliti memberikan materi tentang minat belajar juga tanya jawab kepada siswa yang mengikuti konseling kelompok tersebut 
apa itu belajar, terlihat siswa yang mengikuti konseling kelompok tersebut belum secara jelas mengetahui belajar seperti apa yang baik sedangkan ketika dirumah mereka habiskan dengan bermain, lalu kemudian peneliti menjelaskan apa itu definisi belajar dan bagaimana belajar yang baik. Selanjutnya pertemuan ke-4 pada Rabu, 8 Mei 2019 peneliti memberikan materi tentang motivasi belajar dan juga menggunakan teknik Cognitive Retructuring beserta pembahasanya. Peneliti memberikan motivasi seperti pada (gambar 1) yaitu tentang kesuksesan dimasa depan diraih melalui proses belajar. peneliti membahas masalah motivasi belajar dengan teknik Cognitive Retructuring secara tuntas. Pertemuan ke-5 pada Senin, 13 Mei 2019 selanjutnya diberikan post-test.

Dalam kegiatan post tes ini, cara pengumpulan data sama dengan apa yang telah dilakukan sebelumnya pada pre test kepada 7 siswa setelah diberikan layanan konseling kelokmpok, Adapun hasil perbandingan skor pre - test dan post-test pada tabrel 2.

Tabel 2. Hasil Post - Test

\begin{tabular}{llll}
\hline NO & KODE SUBYEK & Pre - Test & Post - Test \\
\hline 1 & ANH & 68 & 107 \\
2 & AU & 70 & 110 \\
3 & EK & 69 & 114 \\
4 & FE & 69 & 84 \\
5 & GT & 70 & 92 \\
6 & MV & 68 & 135 \\
7 & RD & 70 & 89 \\
\hline
\end{tabular}

Hasil akhir post-test dari 7 siswa tersebut setelah melaksanakan konseling kelompok skors presentase motivasi belajarnya meningkat. Pengujian Hipotesis dalam pelaksanaan penelitian ini diolah dengan menggunakan rumus Wilcoxon yang hasilnya yaitu dari hasil perhitungan wilcoxon antara pre - test dan post - test diperoleh $z_{o}=2,366$. Hasil konsultasi tabel nilai kritis Wilcoxon dengan taraf signifikasi $5 \%$ diperoleh $z_{t} 2,00$; maka perhitunganya $z_{o}=2,366>z_{t}=2,00$. Dengan demikian untuk taraf sigifikasi $5 \%$ perhitunganya $z_{o}>z_{t}$. Maka dengan demikian layanan konseling kelompok dengan teknik cognitive retructuring dalam meningkatkan motivasi belajar siswa rendah.

\section{PEMBAHASAN}

Berdasarkan hasil pengumpulan dan pengolahan data penelitian menunjukkan adanya pengaruh layanan konseling kelompok terhadap motivasi belajar pada siswa kelas XI IPS 3 SMA Negeri 1 
Tawangsari. Pengaruhnya adalah peningkatan motivasi belajar siswa kelas XI IPS 3 SMA Negeri 1 Tawangsari setelah diberikan layanan konseling kelompok.

Oleh karena itu, hipotesis yang berbunyi "ada pengaruh layanan konseling kelompok terhadap motivasi belajar siswa kelas XI IPS 3 SMA Negeri 1 Tawangsari tahun ajaran 2018/2019” dapat diterima kebenaranya.

\section{KESIMPULAN DAN SARAN}

\section{Kesimpulan}

Berdasarkan hasil penelitian dan analisis data yang diperoleh penelitian pada siswa kelas XI IPS 3 SMA Negeri 1 Tawangsari terdapat pengaruh layanan konseling kelompok melalui Teknik Cognitive Retructuring untuk meningkatkan Motivasi Belajar pada siswa kelas XI IPS 3 SMA Negeri 1 Tawangsari Sukoharjo tahun ajaran 2018/2019 hasilnya dapat disimpulkan bahwa motivasi belajar siswa sebelum mendapatkan layanan konseling kelompok rendah dengan skors rata - rata 33,625. Setelah mendapatkan layanan konseling kelompok skor rata - rata naik menjadi 65,63. Berdasarkan analisis data dengan uji tes dapat dilihat bahwa $t_{o}=2,366$ sedangkan tabel nilai kritis wilcoxon pada taraf signifikasi $5 \%$ diperoleh $z_{t}=2,00$ dengan demikian $z_{o}>z_{t}$. Maka dapat disimpulkan bahwa layanan konseling kelompok berpengaruh terhadap motivasi belajar siswa di kelas XI IPS 3 SMA Negeri 1 Tawangsari, artinya semakin besar frekuensi layanan konseling kelompok, semakin tinggi motivasi belajar siswa. 


\section{DAFTAR PUSTAKA}

Ahmadi, A. (2003). Psikologi Umum. Jakarta: Rineka Cipta.

Agung, I. (2012). Menghasilkan Guru Kompeten Dan Profesional. Jakarta: Bee Media

Ali, M. (2004). Psikologi Remaja; Perkembangan Peserta Didik. Jakarta: Bumi Aksara

Anggelis, B. (2005). Confidence: Percaya Diri Sumber Sukses dan Kemandirian. Jakarta: PT. Gramedia Pustaka Utama

Badaruddin, A. (2015). Peningkatan Motivasi Belajar Siswa Melalui Konseling Klasikal. Padang: CV Abe Kreatifindo

Dalyono, D. (2009). Psikologi Pendidikan . Jakarta: Rineka Cipta

Fiah, R. (2016). Efektivitas Layanan Konseling Kelompok Dengan Pendekatan Realita. Jurnal Bimbingan dan Konseling.

Vol. 3, No. 1, Mei 2017. Hal, 47-62, (https://ejournal.radenintan.ac.id, diakses pada tanggal 16 April 2019)

Gie, T. (2004). Cara Belajar Yang Baik Bagi Mahasiswa. Yogyakarta: Gajah Mada Press

Gladding, S. (2012). Konseling Profesi Yang Menyeluruh. Jakarta: PT Indeks

Ismail, I. (2011). Penelitian Pendidikan. Sukoharjo: Univet Bantara Press

KOMPRI. (2015). Motivasi Pembelajaran Perspektif Guru Dan Siswa. Bandung: PT Remaja Rosdakarya Offset

Luxori. (2001). Percaya Diri. Jakarta: Pustaka Al - Kautsar Group.

Mulawarman. (2017). Dampak Konseling Kelompok Teknik Cognitive Retructuring meningkatkan Motivasi Belajar

Siswa. Jurnal Bimbingan Konseling. Vol. 6, No. 2, Desember 2017. Hal 135-140, (https://journal.unnes.ac.id/sju/index.php/jubk, diakses pada tanggal 24 april 2019)

Maulidya, W. (2017). Pengaruh Pemberian Layanan Konseling Kelompok Pendekatan Rational Emotive Theraphy. Jurnal Psikologi Konseling. Vol. 11, No. 2, Hal 16-17, (https://jurnal.unimed.ac.id, diakses pada tanggal 16 April 2019)

Muhibbin, S. (2008). Psikologi Pendidikan Dengan Pendekatan Baru. Bandung: Remaja Rosdakarya

Nugroho, P., Tadjri, I., \& Sutarno, S. (2014). PENGEMBANGAN LAYANAN INFORMASI BELAJAR BERBANTUAN MULTIMEDIA UNTUK MENINGKATKAN KEBIASAAN BELAJAR SISWA. JURnal

Bimbingan Konseling, 3(1). Retrieved from https://journal.unnes.ac.id/sju/index.php/jubk/article/view/3619

Nursalim, M. (2002). Layanan Bimbingan dan Konseling. Surabaya: Unesa University Press

Prayitno. (2009). Dasar - Dasar Bimbingan dan Konseling. Jakarta: Rineka Cipta

Prayitno. (2009). Layanan Bimbingan dan Konseling Kelompok). Jakarta: Ghalia Indonesia

Sardirman. (2011). Interaksi dan Motivasi Belajar Mengajar. Jakarta: Raja Grafindo Persada

Santrock, J. (2014). Psikologi Pendidikan Jilid 2. Jakarta Selatan: Salemba Humanika

Slamet, A., Mutiara. (2015). Uji Wilcoxon Signed Rank Test. Management Analisis Journal. Vol. 1, No. 1, Desember 2015. Hal, 4, (http://journal.unnes.ac.id/sju/index.php/maj), diakses tanggal 23 April 2019)

Sugiarto, P., Samsudi. (2017). Teknik Cognitive Retructuring dalam Konseling Kelompok. Jurnal Bimbingan Konseling.

Vol. 6, No. 1, Juni 2017. Hal, 20-27, (https://journal.unnes.ac.id/sju/index.php/jubk, diakses tanggal 23 April 2019)

Sugiyono. (2013). Metode Penelitian Pendidikan, pendekatan Kuantitatif, Kualitatif dan R \& D. Bandung: Alfabeta

Suharsini, A. (2003). Prosedur Penelitian Suatu Pendekatan Praktek. Jakarta: Rineka Cipta

Sukardi, D. (2000). Pengantar Pelaksanaan Progam Bimbingan dan Konseling Di Sekolah. Jakarta: Rineka Cipta

Suprihatin, S. (2015). Upaya Guru Dalam Meningkatkan Motivasi Belajar Siswa. Jurnal Motivasi Belajar. Vol. 3, No. 1, April 2015. Hal, 73-82, (http://ojs.fkip.ummetro.ac.id, diakses tanggal 16 April 2019)

Triyanto, B., Ismail. (2002). Pedoman Menulis Skripsi (Edisi Revisi). Sukoharjo: Univet Bantara Press

Warsito, H. (2010). Strategi Konseling (Modul). Sukoharjo: Univet Bantara Press 
Widhiarso, W. Retno. (2017). Eksplorasi Karakteristik Item Skala Psikologis. Jurnal Psikologi. Vol. 36, No. 1. Hal 7391, (https://jurnal.ugm.ac.id, diakses pada Tanggal 24 April 2019)

Winkel, W. (2001). Psikologi Pengajaran. Jakarta: Gramedia 